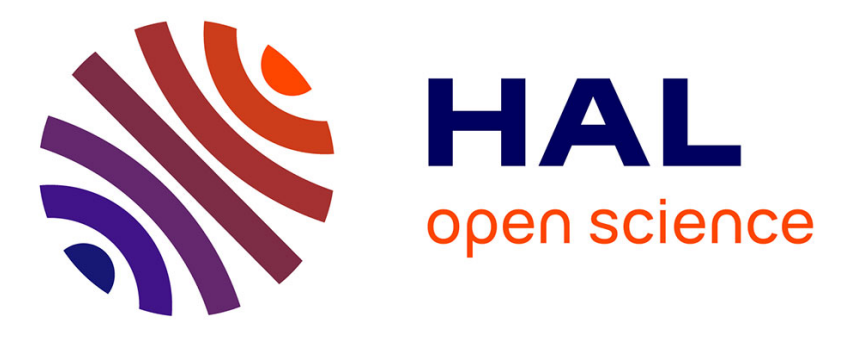

\title{
Educational multimedia and microelectronics : should we think first about the conditions of use?
}

Hugues Choplin, Jean-François Rouet, Dominique Degrugillier, Marite Milon, Renaud Pacalet, Jean Provost, Arnaud Galisson

\section{To cite this version:}

Hugues Choplin, Jean-François Rouet, Dominique Degrugillier, Marite Milon, Renaud Pacalet, et al.. Educational multimedia and microelectronics: should we think first about the conditions of use?. The 3rd European Workshop on Microelectronis Education, May 2000, Aix-en-Provence, France. edutice00000615

\section{HAL Id: edutice-00000615}

\section{https://edutice.archives-ouvertes.fr/edutice-00000615}

Submitted on 8 Sep 2004

HAL is a multi-disciplinary open access archive for the deposit and dissemination of scientific research documents, whether they are published or not. The documents may come from teaching and research institutions in France or abroad, or from public or private research centers.
L'archive ouverte pluridisciplinaire HAL, est destinée au dépôt et à la diffusion de documents scientifiques de niveau recherche, publiés ou non, émanant des établissements d'enseignement et de recherche français ou étrangers, des laboratoires publics ou privés. 


\title{
EDUCATIONAL MULTIMEDIA AND MICROELECTRONICS : SHOULD WE THINK FIRST ABOUT THE CONDITIONS OF USE ?
}

\author{
H. Choplin*, J.-F. Rouet**, D. Degrugillier***, M. Milon****, \\ R. Pacalet*****, J. Provost*****, A. Galisson* \\ * Centre de Ressources en Innovation Pédagogique et Technologies, \\ (CRIPT), Ecole Nationale Supérieure des Télécommunications (ENST) \\ 46, rue Barrault, 75013 Paris \\ ** Laboratoire de Langage et Cognition (LACO-CNRS), Université de \\ Poitiers \\ *** CRIPT, Ecole Nationale Supérieure des Télécommunications de \\ Bretagne \\ **** CRIPT, Institut Nationale des Télécommunications d'Evry \\ ****** ENST
}

\section{A research-development context}

Since 1997, CRIPT (Centre de Ressources en Innovation Pédagogique et Technologie) at the GET (Groupe des Ecoles des Télécommunications which include notably INT Evry, ENST Bretagne and ENST Paris) has coordinated the development of educational multimedia in microelectronics : «L'électronique en questions », which initiates an educational hypermedia collection dedicated to scientific and technical higher education. This product has been developed by several scientific and technical high schools and universities (GET, ENIC Lille, ENSP Strasbourg, EPFL Lausanne, IUT Cachan). It is now available and is aimed at students who are starting their electronics program. Its development involved important contributions in psychological evaluation provided largely by and with the Language and Cognition Laboratory LACO-CNRS at the University of Poitiers. This paper presents the results of this evaluation and especially the concrete recommendations it seems to imply.

\section{Evaluation : aims, hypotheses and procedures}

This evaluation concerned two multimedia sequences (each one involving about ten minutes of « linear reading ») dedicated respectively to adders (digital electronics) and transistors (analog electronics). Our aim was to evaluate the impact of two parameters on the learning process :

- $\quad$ multimedia design and especially the importance of images and animations with regard to the text (spoken or written);

- $\quad$ the task given to the student before using of the sequences.

Our hypotheses were : 
- images and animations can enable students to solve engineering problems better than text ;

- students use different learning strategies when the purpose of the task is to solve a problem and when it is to memorize.

Two designs for each sequence were developed. The first design (called «image ») is founded on a design which favors images and animations for four reasons : images and animations include rich information; they are systematically provided before the text which is associated with them ; their value is spatially increased on the screen (they are often located on the center of the screen); they raise the level of interactivity because the user can control the unfolding of the sequence. The second design (called «text $»)$ implements contrary design options (animations have disappeared and images are only decorative illustrations ; they are also systematically presented after the text ; spatially devalorized ; associated with «poor» interactivity).

26 students were recruited. We gave them a task which was either to memorize the information or to solve an engineering problem. After having studied one design (« image » or « text ») of a sequence for 20 minutes, each student had :

- on the one hand to answer questions concerning factual knowledge (for example : "What is the link between the output current and the input voltage in a bipolar transistor? ») and

- on the other hand to solve an engineering problem corresponding to the sequence studied.

These questions and problems rely of course on the concepts included in the two sequences (we do not include the whole psychological methodology in this paper : preand post-test scores, etc.).

\section{Evaluation results}

The evaluation brings to the fore two major results which are independent of the content (transistors or adders) :

- surprisingly, the «image » design does not seem to imply the best (or lower) performance for solving the problems (it has no effect on the acquiring of factual knowledge, either); to be precise, the computer recordings of the students' activity show that they did not really treat the images and animations;

- the task is very significant: the students who had the task of « solving a problem» performed better on problems than those who had the task « of memorizing ». But the latter answered the factual questions better.

\section{Discussion}

The effect of the task shows that the learner's way of studying is not the same when he is in a problem solving context or in a memorizing one. In particular, a memorization task seems to «prevent » the student from finding a complete and justified solution to the problem. This effect is independent of the type of design («image » or « text»). This suggests that the «wealth» of the medium cannot make up for an unfavourable 
learning context (task). Finally, it shows that these students have a good capacity for self-regulation. It allows them to adapt their way of studying to the demands of the task. This is not always the case with students (Butler \& Winne, 1995).

The absence of psychological effects linked to the images and animations is more difficult to understand. First, it does not show that images and animations are systematically useless - even if several recent research projects (Wright, Milroy \& Lickorish, 1999) suggest that the effect of animation could be disturbed by many factors : ergonomical (too poor or overloaded animations, too slow or too fast rhythm) and/or pedagogical (the animations considered as a «show » may lead the learner to a certain passivity). In fact, the evaluation and literature's results lead us to think that the use of images and animations should not be systematic but should be subordinated to four main parameters :

- $\quad$ the task given to the student before using the multimedia ;

- the student's attitude to knowledge. It is very possible that the images and animations included in our «image » designs concerned points which were not difficult and abstract enough for the students we had solicited: were their contribution sufficiently significant with regard to the (spoken and written) text offered ? (Levin, 1987);

- $\quad$ the student's attitude to media. "Our» students seem to consider images and animations in general as not really fundamental for learning (for example they are considered to be subordinate to mathematical equations) (Choplin, 99). These two last points (attitude to knowledge and to media) suggest that the images and the animations included in our « image » designs may have more effect on other types of students.

- $\quad$ the study time. It is very possible that assimilating images and animations takes a long time, especially as our «image» designs (with images and animations appearing before text) aimed to stimulate the student's questioning. But is it really possible to puzzle about electronics in 20 minutes ? In other words, the students may have benefitted more from the «image » design if we had allowed more time (longer than 20 minutes) to study the sequences or if the students had studied in a temporal context which was closer to that of «self regulated learning ».

\section{Recommendations}

In general, these results confirm that pedagogical innovation is not essentially determined by technological conditions and that it poses complex problems. In fact, our results lead to design educational multimedia with dependance on non-technological requirements: psychology of the student, the task given to him (especially by the teacher), the study time. Therefore, before designing and developing pedagogical multimedia, it seems to be essential to define the pedagogical context (the characteristics of the student, the way the teacher asks to the student to use the multimedia, the study time) in which the multimedia will be used.

From a more concrete point a view, it seems to be possible to require educational multimedia designers : 
- to precisely define the goals of the reading of the multimedia. For example, from a pedagogical point of view focused on the learner's activity, to define sequences through questioning (for example: "How can you design a high performance adder with logical gates? », rather than the statement «The adder's design») which could lead the student to solve a problem (and not to memorize information);

- to choose images and animations directly connected with this goal (in our example : it is no use developing animations describing the way the logical gate operates if the aim is to answer to the question : «How can you design a high performance adder with logical gates? »);

- to concentrate the development of these images and animations - whose time requirements are always strong - on points which are difficult and abstract for the students at whom the multimedia is aimed. From this point of view, it is not certain that the animated diagram of a circuit is systematically useful for learning. Il is probably important to define images and animations whose function is not only to represent or to organize the text but also to interpret it (then the graphics describe unfamiliar, difficults or abstracts concepts) or, even better, to transform the text (then they transform it in order to have a direct impact on the learner : they target the crucial information to be learnt for example by recoding it in a more concrete and memorizable way) (Levin, 1987) ;

- to increase the value of images and animations by adding a sound track. The comments do not necessarly have to be explanatory: substantial or dense information seems to be treated with more difficulty when it is spoken than when it is written. They can help the student to understand the importance of the images and animations and to treat them (the evaluation also led the students to complete a questionnaire concerning the balance and the role of the media : images and animations, texts, sounds). Thus, they are not directly connected with the content but are rather «meta» sounds (for example : «Be careful, we are now going to study a crucial or/and very difficult point concerning the design of adders!»). These comments seem to be required by the students because they seem to be able - at least partly - to make up for the teacher's absence.

We intend to develop these recommendations in future developments of our educational hypermedia collection «en questions ».

\section{References}

Butler, D.L. \& Winne, P.H. (1995). Feedback and self-regulated learning : A theoretical synthesis. Review of Educational Research, 65, 245-281.

Choplin H. (1999). Les élèves, Prisméo et les hypermédias pédagogiques : éléments d'analyse in Choplin $\mathrm{H}$ (éd)., Prisméo, une expérience de cédérom pédagogique (96-98), Rapport final : bilan et perspectives, CRIPT, GET , 1999.

Levin J.R., Anglin G.J., Carney R.N. On empirically validating functions of picture in prose in H.A. Hougton, D.M. Willows (eds), The psychology of illustrations, vol. 1 : basic research, New York, Springer Verlag, 1987.

Wright, P., Milroy, R., \& Lickorish, A. (1999). Static and animated graphics in learning from interactive texts. European Journal of Psychology of Education, 14, 203-224. 